\title{
Placement of covered self-expanding metal stent to treat razor blade-induced esophageal hemorrhage
}

A prisoner (42 years old) was admitted to a hospital emergency department after swallowing razor blades in a suicide attempt. The patient had no symptoms such as retrosternal pain or dysphagia. The blades were extracted endoscopically, which caused longitudinal esophageal lesions and acute bleeding. The insertion of a Sengstaken-Blakemore tube initially stabilized the patient. After the tube had been deflated, massive hematemesis with hypovolemic shock required the insertion of a self-expanding metal stent (SEMS) (SX-Ella DANIS Stent; ELLA-CS Co., Hradec Kralove, Czech Republic) ( $\bullet$ Fig. 1).

During hospital treatment, the patient developed a bilateral pulmonary embolism that needed high intensity anticoagulation. The patient then suffered again from severe hematemesis. Massive transfusion (hemoglobin $5 \mathrm{mg} / \mathrm{dl}$ ), orotracheal intubation, and cardiopulmonary resuscitation was necessary. Upper gastrointestinal endoscopy showed pulsatile arterial bleeding. Computed tomography (CT) angiography revealed an aortoesophageal fistula, probably also of traumatic origin as a consequence of the razor blade extraction ( $\bullet$ Fig. 2).

An endoluminal stent graft (Zenith Endovascular Graft; Cook Ltd., Limerick, Ireland) was implanted in the aorta via the left femoral artery ( $\bullet$ Fig. 3 ).

The patient recovered well; even under high-intensity anticoagulation, the patient experienced no bleeding when the stent was extracted.

The ingestion of foreign bodies is frequently seen in pediatric or psychiatric patients, and can cause severe morbidity and mortality. Endoscopy is an important diagnostic and therapeutic tool, although foreign bodies usually pass spontaneously $[1,2]$. Even ingestion of potentially harmful objects such as razor blades seldom leads to severe complications [3]. New stent devices offer a safe and effective treatment option for acute and refractory variceal bleeding $[4,5]$ and severe injuries of the gastrointestinal tract [6]. An aortoesophageal fistula is a rare complication of swallowing a foreign body, typically fish or chicken bones [7].

In our patient the esophageal bleeding was stopped effectively using an atrau-
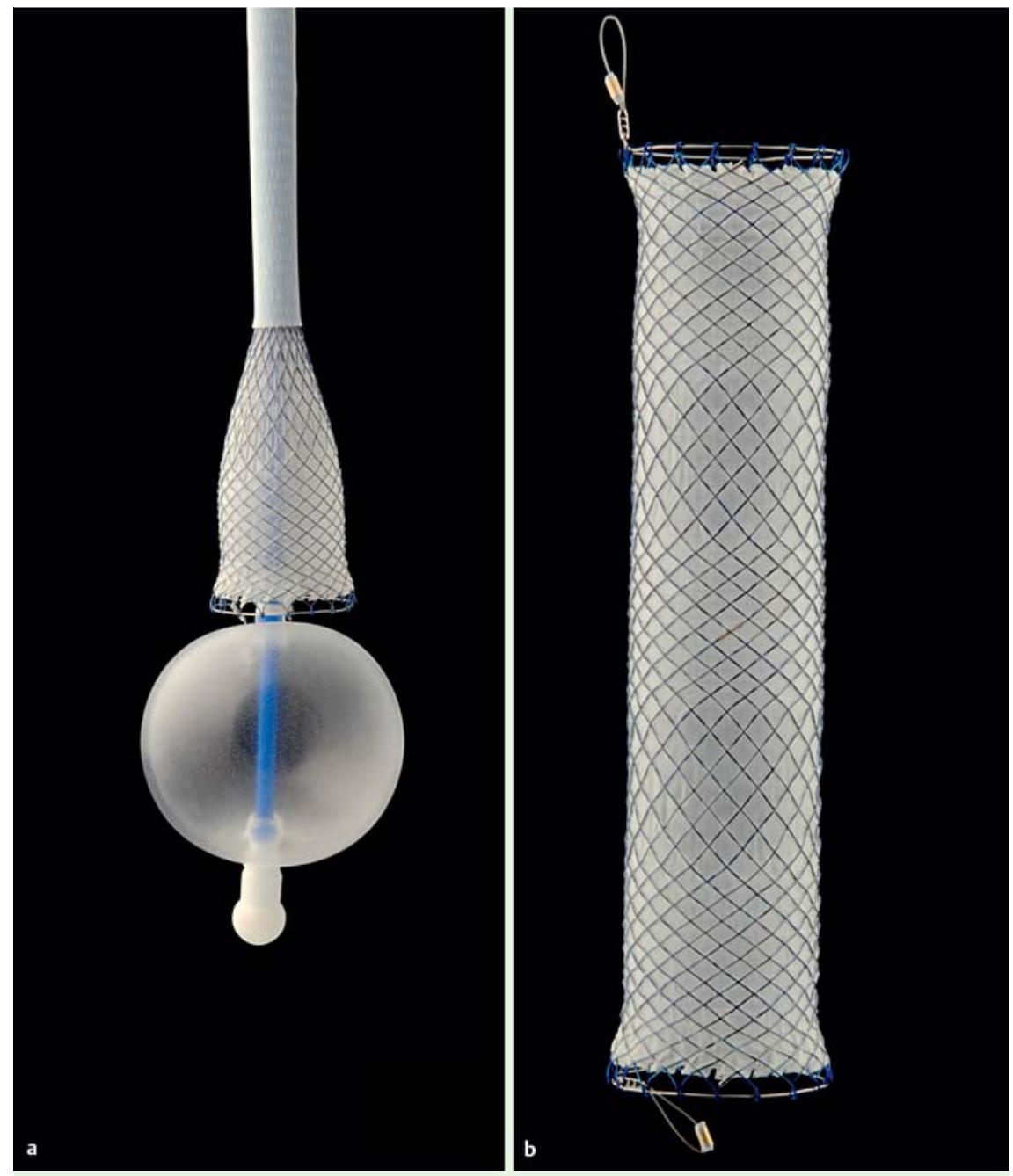

Fig. 1 The SX-Ella DANIS stent, which is atraumatic, stopped esophageal bleeding following razor blade ingestion: a Inflation of the balloon below the lower esophageal sphincter allows correct positioning of the stent. $\mathbf{b}$ Completely self-expanded metal stent.

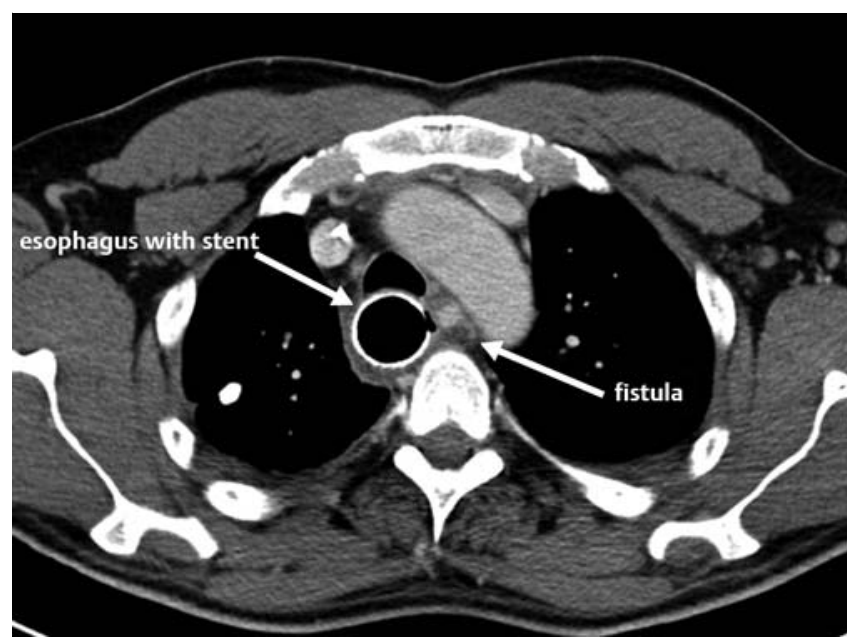

Fig. 2 Computed tomography (CT) scan of the aortoesophageal fistula due to a thoracic aorta pseudoanuerysm located $1 \mathrm{~cm}$ distal to the subclavian artery on the descending thoracic aorta. The neck of the fistula starts at the level of the aortic arch. 


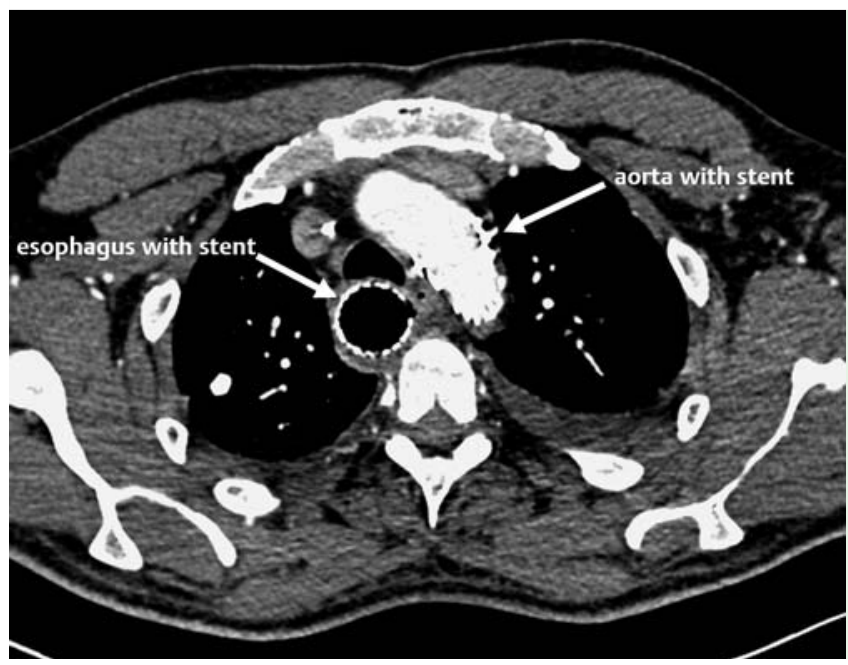

Fig. 3 Computed tomography (CT) scan showed the endoluminal and endovascular stent grafts to be in the correct positions, with no important leakage.

matic membrane-covered SEMS. The aortoesophageal fistula that was secondary to the treatment was treated by endovascular stent grafting. Both techniques may be an alternative to surgical intervention. These results for esophageal bleeding have to be confirmed by randomized controlled trials with a large number of patients.

\section{Competing interests: None}

Endoscopy_UCTN_Code_CPL_1AH_2AK

Endoscopy_UCTN_Code_TTT_1AO_2AZ
E. Kaya ${ }^{1}$, P. Lenz ${ }^{2}$, P. Lebiedz¹, K. Baumgarten $^{3}$, J. Wessling ${ }^{4}$, D. Domagk ${ }^{2}$

1 Department of Cardiology and Angiology, University of Münster, Germany,

2 Department of Medicine B, University of Münster, Germany,

3 St. Bonifatius Hospital Lingen, Germany

${ }^{4}$ Department of Clinical Radiology, University of Münster, Germany

\section{References}

1 Velitchkov NG, Grigorov GI, Losanoff JE et al. Ingested foreign bodies of the gastrointestinal tract: retrospective analysis of 542 cases. World J Surg 1996; 20: 1001 -1005
2 Weiland ST, Schurr MJ. Conservative management of ingested foreign bodies. J Gastrointest Surg 2002; 6: 496-500

3 Blaho KE, Merigian KS, Winbery SL et al. Foreign body ingestions in the Emergency Department: case reports and review of treatment. J Emerg Med 1998; 16: 21 - 26

4 Hubmann R, Bodlaj G, Czompo M et al. The use of self-expanding metal stents to treat acute esophageal variceal bleeding. Endoscopy 2006; 38: 896-901

5 Wright G, Lewis H, Hogan B et al. A self-expanding metal stent for complicated variceal hemorrhage: experience at a single center. Gastrointest Endosc 2010; 71: 71 - 78

6 von Renteln D, Walz B, Riecken B et al. Endoscopic management of acute esophageal dissection by using a covered, self-expanding metal stent (with video). Gastrointest Endosc 2009; 69: 577-580

7 Nandi P, Ong GB. Foreign body in the oesophagus: review of 2394 cases. Br J Surg 1978; 65: $5-9$

Bibliography

DOI $10.1055 / \mathrm{s}-0030-1255699$

Endoscopy 2010; 42: E201 -E202

(c) Georg Thieme Verlag KG Stuttgart · New York . ISSN 0013-726X

Corresponding author

D. Domagk, MD

Department of Medicine B

University of Muenster

Albert-Schweitzer-Straße 33

D-48149 Muenster

Germany

Fax: +49-251-83-47570

domagkd@uni-muenster.de 